\title{
A defesa da saúde pública através dos conselhos municipais de saúde
}

\author{
Public health defense through municipal councils of health
}

\author{
La defensa de la salud pública a través de los consejos municipales de salud
}

\section{Recebido: 15/10/2016 \\ Aprovado: 04/04/2017 \\ Publicado: 03/08/2017}

\section{Andréia Aparecida Reis de Carvalho Liporoni1}

Este artigo tem como objetivo refletir sobre a participação e o controle social através dos conselhos municipais de saúde. Para tanto, utilizou dados de uma pesquisa realizada pelo Conselho Nacional de Saúde, com dados divulgados em 2016, em que 4.539 conselhos municipais de saúde participaram do cadastro de dados no Sistema de Acompanhamento dos Conselhos de Saúde (SIACS) brasileiros. Por este estudo, se verificou que a representatividade dos conselhos de saúde ainda é frágil, bem como os conselheiros não procuram suas bases para discussão de assuntos pertinentes à coletividade. Isto mostra a necessidade de que os conselheiros recebam capacitação. Aliadas a isso, a vocalização das ações e as deliberações dos conselhos também se mostram frágeis.

Descritores: Participação social; Participação nas decisões; Conselhos de saúde.

This article aims to reflect on participation and social control through municipal health councils. To do so, it used data from a survey conducted by the National Board of Health of Brazil, which was released in 2016. 4,539 municipal councils participated in the recording of health data in the System of Health Council Oversight (SIACS). This study found that the representativeness of health councils is still fragile, and the counselors do not seek the people they represent to discuss matters pertaining the community. This shows the need for board members to receive training. In addition, the publicity of actions and decisions taken by the board is also far from widespread.

Descriptors: Social participation; Management quality circles; Health councils.

Este artículo tiene como objetivo reflexionar sobre la participación y el control social a través de los consejos municipales de salud. Para esto, se utilizaron datos de una investigación realizada por el Consejo Nacional de Salud del Brasil, con datos divulgados en 2016, con 4.539 consejos municipales de salud que participaron del registro de datos en el Sistema de Acompañamiento de los Consejos de Salud (SIACS) brasileros. Por medio de este estudio se verificó que la representatividad de los consejos de salud aún es frágil y que los consejeros no buscan sus bases para discusión de asuntos pertinentes a la colectividad. Esto demuestra la necesidad de que los consejeros reciban capacitación. Aliado a esto, la vocalización de las acciones y deliberaciones de los consejos también se muestra frágil.

Descriptores: Participación social; Participación de los empleados; Consejos de salud.

\footnotetext{
${ }^{1}$ Assistente Social. Mestre em Ciências Médicas. Doutora em Serviço Social. Docente do Curso de Serviço Social da Faculdade de Ciências Humanas e Sociais - UNESP - Campus de Franca, SP/Brasil. 


\section{INTRODUÇÃO}

$\mathrm{A}$ partir dos anos 1990, período de implementação dos princípios estabelecidos pela Constituição Federal de $1988^{1}$ com a ampliação dos direitos civis e políticos, além da participação da sociedade na gestão administrativa, presencia-se uma generalização do discurso sobre a importância da participação e do controle social sobre as decisões governamentais.

A participação e o controle social podem ser exercidos através dos conselhos de políticas públicas, e no caso da saúde, pelos conselhos municipais de saúde.

Os conselhos de políticas públicas podem ser considerados como um dos mecanismos deliberativos em curso pelo mundo. Abarca um grande número de pessoas debatendo sobre os assuntos que interessam à coletividade, e, portanto, teve grande evolução na história da participação ${ }^{2}$.

A participação dos cidadãos remonta ao mundo grego, e apresenta, no curso da história até a contemporaneidade, conquistas, mas também limites e resistências.

A democracia ateniense cujo início se dá em 5 a.C. tem seu fim em 322 a.C, e marca o surgimento do governo democrático - com contorno representativo - forma que se presencia na contemporaneidade - apenas cerca de dois milênios depois ${ }^{3}$.

Na cidadania grega, Aristóteles definiu o cidadão como "todo aquele que tinha o direito (e consequentemente, também o dever) de contribuir para a formação do governo, participando ativamente das assembleias nas quais se tomavam as decisões que envolviam a coletividade". Entretanto, mulheres, crianças, estrangeiros e escravos não eram considerados cidadãos, e diante deste limite não era possível considerar esta participação universal ${ }^{3}$.

Na Idade Média, no modo de produção feudal, uma sociedade dividida hierarquicamente e nutrida de valores e crenças de cunho religioso, a cidadania tinha sua existência inviabilizada em função de inúmeros aspectos de ordem sócioeconômico-cultural ${ }^{4}$.

No Renascimento (entre os séculos XIV e XVI), ocorre uma profunda transformação na visão de mundo do período medieval e nasce a concepção individualista que deu fundamento à visão burguesa. No século XV, surge o Estado absolutista, fruto da aliança entre o rei e a burguesia, com vistas a melhorias no sistema comercial (condições das estradas, regras comerciais, entre outras questões), mas com total ausência de qualquer tipo de participação. As cidades queriam independência, fruto de reivindicações políticas, organizadas pela nascente classe burguesa comercial que defendia seus interesses da nobreza feudal, uma vez que objetivava total autonomia ${ }^{4}$.

A cidadania preconizada pelos renascentistas estava, intrinsecamente, ligada aos interesses da classe dominante, e para a grande maioria da população, a participação não existia ${ }^{4}$.

Cem anos depois (1789) acontece a Revolução Francesa, com a tomada do poder pela burguesia e a instituição do modelo de Estado liberal. Já nos fins do século XIX, na Europa, a cidadania passa a conter os chamados direitos políticos, que na verdade eram negados à maioria dos trabalhadores, sendo 0 voto facultado apenas aos proprietários. Os sindicatos eram proibidos e os partidos de massa não legalizados, levando a incessantes lutas de classes trabalhadoras ${ }^{4}$.

A partir do ideal de democracia preconizado pelos atenienses e avaliando todas as mudanças que ocorreram até o século em questão, destacam-se as privações e os limites que a população sofreu, tendo em vista que a primazia do poder da classe burguesa ou daqueles que possuíam riqueza era incontestável.

A evolução histórica levou a mudanças no sistema de governo. Com as mudanças estruturais no sistema, a revolução industrial, a ideia da revolução burguesa e a complexidade da sociedade, aparece a possibilidade da representação através de eleições e se estabelece o sistema partidário. Este sistema é um processo democrático que determina um método político para se chegar a decisões políticas e administrativas, transformando-as em um método para a constituição de governos através de um conjunto de regras. 
A legitimidade da democracia está no fato de que o poder estatal é autorizado a partir de decisões coletivas de todos os cidadãos, daí o uso da palavra soberania. Entretanto, é possível de fato que o povo governe nos tempos atuais? ${ }^{5}$

0 procedimento democrático determina um método político para se chegar a decisões políticas e administrativas, transformando-as em um método para a constituição de governos. Ou seja, o povo é soberano somente na capacidade de votar e eleger seus representantes.

A democracia constitui-se em um conjunto de regras entre as quais se destaca o peso igual dos votos e a ausência de distinção econômica, social, religiosa e étnica na constituição do eleitorado. Entretanto, a participação acaba ficando sem incentivos em função da complexidade da sociedade nas democracias modernas 5 .

Neste sentido, a democracia tem destaque no campo político durante o século $\mathrm{XX}$, tornando-se um processo hegemônico ao fim da $2^{\text {a }}$ guerra mundial, mas "implicou em restrição das formas de participação e soberania em torno de um processo eleitoral para a formação de governos"6.

A democracia moderna desde logo já não correspondia exatamente ao governo de todos. 0 caráter centralizador do novo sistema propõe imediatamente uma assimetria de poder entre os cidadãos, que dificilmente traduz um governo de todos; e a separação que o liberalismo operou entre o poder político e o poder econômico revolucionaria o mundo saído do feudalismo, criando um poder privado, econômico, cuja gestão é retirada do cidadão comum ${ }^{7}$.

Os países centrais consolidaram a concepção hegemônica de democracia liberal, como modelo único e universal aproveitado ou consagrado pelo Banco Mundial e pelo Fundo Monetário Internacional, principalmente ao transformá-la em condição política para a concessão de empréstimos ou ajuda financeira. Este modelo de democracia liberal procura "[...] estabilizar a tensão controlada entre democracia e capitalismo". De um lado priorizando a acumulação de capital e de outro lado a limitação da participação cidadã que poderia fortalecer as reivindicações sociais e sobrecarregar com demandas sociais o Estado, colocando em risco a prioridade da acumulação ${ }^{6}$.

Assim, chamar a população a tomar parte "em algum momento da construção de uma política ou serviço público é mais necessário ao sistema capitalista quanto maior o estágio de desenvolvimento das forças produtivas, sempre com o intuito de reduzir custos de serviços públicos"8.

$\mathrm{Na}$ democracia liberal espera-se que o Estado se abstenha de interferir na esfera dos direitos do cidadão e na economia, isto é, que seja um Estado preocupado em preservar a democracia não interferindo na economia.

Diante da questão exposta, a doutrina democrática imaginou um Estado sem corpos intermediários, característicos da sociedade corporativa, das cidades medievais e do estado de camadas ou de ordens anterior à afirmação das monarquias absolutas. Ou seja, uma sociedade política na qual o povo soberano é composto por tantos indivíduos (uma pessoa, um voto) ${ }^{9}$.

No entanto, o que se vê na sociedade democrática é exatamente o oposto. Os grupos tornaram-se relevantes, pois encontra-se associações de diversas naturezas, partidos políticos de diversos pensamentos ideológicos. Não existe a soberania, mas o jogo de interesses, ao mesmo tempo políticos e particulares, o que em muito contribui para a crise da democracia representativa que se tem presenciado a partir das últimas décadas.

$\mathrm{Na}$ contemporaneidade, os partidos políticos tiveram e têm significativa importância, apesar de apresentarem-se insuficientes na manutenção da democracia. É possível apontar, entre outras questões, a profissionalização dos políticos, e a separação dos interesses dos partidos e dos próprios políticos, que leva à falta de confiança nos partidos políticos e ao distanciamento entre os representantes e seus representados.

Os movimentos sociais apresentaram grande evolução nas últimas décadas. $\mathrm{Na}$ abordagem marxista, o conceito de participação não é encontrado de forma isolada, mas sim articulado a duas outras categorias de análise: lutas e movimentos 
sociais, ou seja, os movimentos sociais caracterizam-se por dois fatores: pela natureza da classe social que emerge e pelo seu caráter de luta, seja ele reformista, reacionário, revolucionário ou conservador ${ }^{10}$.

As lutas sociais sempre existiram sob o prisma da igualdade, objetivando melhores condições de vida a partir da manifestação de grupos sociais excluídos e da necessidade de reivindicar. É possível citar, entre outros, os movimentos ecológicos e o movimento das mulheres (feminista), que não passaram pelo crivo dos partidos políticos. Estes últimos (os partidos) por si só foram perdendo a capacidade de monopólio da captação das demandas.

Destaca-se, ainda, que no século XXI existem ações coletivas que se manifestam pela paz, contra a violência, contra o desemprego, por melhorias salariais, contra o neoliberalismo, a guerra.

No Brasil, em toda formação sócio histórica houve importantes lutas, destacando-se as mais recentes como o Movimento Sanitário na década de 1980, o Movimento dos Sem Terra (MST) - que ainda está em marcha, o movimento das "Diretas Já", na luta pela plena redemocratização deste país, o movimento GLBT, e mais recentemente, em 2013, a grande mobilização em torno dos valores das tarifas de transporte público na cidade de São Paulo, que desencadeou um processo de mobilizações e reivindicações por todo o país.

No período ditatorial, a participação ficou muito atrelada aos planos de desmonte à ditadura, propiciando que grupos organizados se manifestassem contrários à ordem ditatorial estabelecida. A história nos conta que foram momentos difíceis, de repressão política, civil e atitudes autoritárias por parte do governo estabelecido.

Estes movimentos tinham diferentes origens e objetivos, mas convergiam na luta contra o regime autoritário. Com a redemocratização determinou-se a anistia política, a legalização partidária e sindical, o direito de associação, e a convocação de eleições.

A democracia brasileira "efetivou-se mais pela institucionalização do Estado democrático do que pela realização do processo de participação popular". Esta questão aponta que isso manteve o "distanciamento da participação popular do acompanhamento e gerenciamento do Estado democrático, mesmo com o reconhecimento da responsabilidade da sociedade" 11 .

Destaca-se ainda o aprofundamento da crise do capital e a expansão do neoliberalismo, que teve como legado: o aumento do desemprego, os cortes nos gastos sociais, a legislação ante sindical, o amplo programa de privatização, as mudanças nas relações de trabalho e nas relações entre o Estado e a sociedade civil, exigidas pelas políticas de ajuste, tal como recomendadas pelo Consenso de Washington ${ }^{12}$.

Com relação à participação política, fica claro que os períodos ditatoriais (não só no Brasil) minaram qualquer possibilidade de participação civil nos mandos públicos. Com a redemocratização destes países, nas últimas décadas do século XX, acontece a emergência de se entender o que é a democracia e a necessidade de processos participativos mais amplos.

Em resumo, o que se pode apontar é que na década de 1960 a participação acontece de maneira pontual, com movimentos de protestos contra a ditadura militar aliados a movimentos de expressão como o Movimento dos Direitos Humanos e Femininos. Os países redemocratizaram-se e reivindicaram mais participação nas decisões, o que foi ampliado através da Constituição de vários países, entre eles o Brasil.

Uma vez determinada a participação como conquista da sociedade o desafio é fazêla mais intensa. Ou seja, apenas votar não é o ideal da democracia contemporânea, situação em que os cidadãos são meros expectadores das decisões governamentais.

0 ideal e, portanto, um desafio, é que os cidadãos possam exercer a participação articulando-se com o sistema político, tendo uma participação mais ativa, mais comprometida e fiscalizatória na tomada de decisões que afetam as comunidades.

A Constituição Federal de 1988 $^{1}$ possibilitou a participação da sociedade, e 
uma das formas efetivas é que esta seja realizada através dos conselhos de políticas públicas. Assim essa participação é entendida também como controle social. Controle social nos mandos públicos.

Este artigo traz uma reflexão sobre a Constituição Federal de $1988^{1}$ no âmbito das políticas sociais, e em especial pelos conselhos municipais de saúde, instituídos pela Lei Orgânica da Saúde n. 8.142 de 199013. Assim, este artigo tem como objetivo refletir sobre a participação e o controle social através dos conselhos municipais de saúde.

\section{MÉTODO}

Este artigo foi construído a partir do referencial teórico da participação na democracia, sobre os conselhos de políticas públicas, e, em especial, sobre o controle social na saúde.

Estudo realizado em 2016 com base também em documentos como: Resolução $333 / 2003^{14}$ e Resolução 453/201215, e outras pesquisas $^{16}$.

\section{RESULTADOS}

Observaram-se dados obtidos em uma pesquisa de doutorado realizada em 2010, envolvendo 06 conselhos municipais de saúde da Direção Regional de Saúde VIII no Estado de São Paulo, através de pesquisa documental e bibliográfica, com abordagem quantitativa e qualitativa.

Foi avaliada a estrutura organizacional dos conselhos de saúde em consonância com resoluções, a captação das demandas da população pelos conselheiros, assim como o modo em que estes devolvem as informações para seus representados, e sua capacitação, como uma das possibilidades de qualificar os conselheiros para esta função, também política.

Também foram avaliados os dados de uma pesquisa realizada pelo Conselho Nacional de Saúde (CNS) do Ministério da Saúde.

\section{DISCUSSÃo}

0 retorno da democracia, no Brasil, na década 1980, vincula o fortalecimento da democracia “[...] à condiç̧ão das instâncias de participação (o voto, as eleições e os partidos) como também a ampliação de novos canais participativos" que se encontra na institucionalização dos conselhos de políticas públicas (saúde, criança e adolescente, idoso, assistência social, dentre outros), e nas formas de compartilhamento de poder como na confecção e elaboração dos orçamentos participativos. Nestes contextos, os cidadãos podem direcionar suas vontades de acordo com o interesse público ${ }^{17}$.

A noção de interesse público envolve "uma concepção de bem comum politicamente pactuado e moralmente fundado - e um conjunto de regras ou procedimentos de julgamento a serem seguidos - pertinentes à questão de direitos". Assim, o conceito de público inscreve-se no campo democrático ${ }^{18}$.

Assim, de acordo com os princípios da democracia participativa e deliberativa nas políticas públicas, esta pode se dar através da participação institucionalizada dos conselhos - que alteram os modos de formulação e implementação de políticas e passam a ser uma maneira de interlocução entre Estado e sociedade com um aumento significativo desde a década de 1990, visto ser a participação uma das formas de se exercer o direito constitucional ${ }^{16}$.

No Brasil, os conselhos de políticas públicas apresentam características centrais do processo deliberativo. A principal característica deste formato deliberativo está no fato do mesmo ser um espaço de articulação entre Estado e sociedade, no qual as decisões sobre políticas públicas podem envolver um processo de discussão e busca de acordos públicos a partir da inclusão de diferentes segmentos da sociedade, diretamente envolvidos.

Os conselhos de políticas públicas podem ser chamados de "[...] formatos institucionais que favorecem a capacidade dos governos de captar interesses dos cidadãos e agir conforme esses interesses" onde "[...] os governos possam ser induzidos ou constrangidos a trabalhar pelo interesse público"19.

Um dos principais objetivos dos conselhos é o controle das iniciativas do 
Estado através da participação dos cidadãos, de modo que os mesmos contribuam na tomada de decisões.

Essa perspectiva fiscalizatória das políticas públicas tem uma história recente, datada do final da década de 1970 e modificada a partir da Constituição Federal de 1988. É "resultado de um processo de luta e mobilizações que iniciaram nos anos 1960, intensificando durante o período militar e que tem o seu início na luta pela efetivação da saúde pública universal" 16 .

Nos anos 1960, início da ditadura no Brasil, haviam movimentos que foram desencadeados em função das demandas por atendimentos básicos à maioria da população. Era um momento de repressão política, aprofundamento das desigualdades sociais, e exclusão de vários direitos civis, apesar do desenvolvimento econômico vivido nesta década. É, neste contexto que emergem os vários movimentos sociais como as Comunidades Eclesiais de Base (CEB), o Clube de Mães, o Movimento Contra a Carestia, e o Movimento da Saúde na Zona Leste. Este último resultou a princípio na formação de comissões de saúde na zona leste, e ao final da década de 1970, na eleição de um conselho de representantes das comunidades para fiscalizar o funcionamento da saúde, na região ${ }^{16}$.

Nesta época, os Conselhos de Saúde expressam "[...] uma das ideias fundadoras da Reforma Sanitária que postulava a democratização de acesso a bens e serviços propiciadores da saúde, mas também a democratização do acesso ao poder". É importante destacar que a "agenda da reforma sempre teve nas propostas participativas a marca de sua preocupação com os mecanismos de funcionamento do Estado e não só com os resultados redistributivos de suas políticas". Daí o emprego simultâneo das consignas "Democracia é saúde" e "Saúde é democracia", emblema da Reforma Sanitária enquanto reforma também da política, no sentido de que o direito universal à saúde deveria ser acompanhado, garantido mesmo, pelo direito à participação no poder ${ }^{18}$.
0 controle social tal qual se conhece na atualidade teve seu início no setor saúde, motivado pela Reforma Sanitária com vistas a um sistema de saúde público universal, participativo e de qualidade.

O controle social nasce do texto da Constituição Cidadã de $1988^{1}$ a partir da importância dos movimentos sociais, de profissionais de saúde e de lideranças populares lutando pelo direito à saúde, ou seja, os direitos assegurados na Constituição Federal são resultados da mobilização popular, durante o período constituinte.

Neste momento, os atores da sociedade civil muito se movimentaram e reinscreveram na Constituição Federal alguns dos seus anseios, reforçando direitos antigos e instituindo novos (saúde, educação, assistência social), reforçando o papel do Estado na efetivação dos mesmos ${ }^{18}$.

Entre os anos de 1985 e 1986, a Assembleia Constituinte (AC) passa por forte mobilização popular no conjunto das políticas sociais para propor emendas constitucionais como a emenda da saúde, da assistência social, das reformas agrária e urbana, as quais, no seu conjunto, são reformas muito importantes para toda a população brasileira, sendo que em todas elas aparece a questão da participação popular na elaboração, monitoramento e fiscalização das políticas públicas ${ }^{2}$.

Outra questão importante é que ao final da AC acontece a reivindicação de que esta participação seja institucionalizada. A Constituição Federal de 1988 formaliza a participação nas políticas públicas e as leis orgânicas das diversas políticas (saúde, assistência social, criança e adolescente através do seu estatuto, no também estatuto das cidades e outros) dão a normatização do formato que terão os conselhos em cada instância.

Neste primeiro momento, os conselhos conseguem um formato institucional nas grandes cidades, mais precisamente nas cidades em que a sociedade civil mais atuava nas políticas públicas através dos movimentos sociais.

Outra questão é que a participação não acontece de maneira homogênea nem mesmo 
nas capitais brasileiras. Em cidades como São Paulo, Rio de Janeiro, Belo Horizonte e Porto Alegre, este movimento foi muito mais organizado do que em outras capitais, que tiveram a implantação desses espaços participativos somente depois do processo Constitucional. Como exemplo, a cidade de São Paulo obteve a legislação formalizando os conselhos antes da própria promulgação da Constituição Federal².

Algumas políticas públicas acabam por ter uma formatação mais significativa da participação institucionalizada em detrimento de outras. São elas: saúde, assistência social, criança e adolescente, políticas urbanas e de meio ambiente.

Essa ascendência de algumas políticas sobre outras tem a ver com a questão do próprio formato dos movimentos sociais, com certas características do Estado e também graças às legislações especificas de cada área²

A área da saúde, por ter tido a primeira organização de conselho e em função de sua própria dinâmica, é a área que mais congregou conselhos formalizados e de maior longevidade.

A participação social é definida na Constituição Federal de 1988, e na questão saúde é regulamentada através da Lei Orgânica da Saúde 8142/199013. Os conselhos são um dos instrumentos de participação cidadã, e existem em todos os municípios brasileiros - exigência legal para o recebimento das verbas da União e dos Estados pelos municípios. Essa exigência para recebimento de verbas também envolve a aprovação do Plano de Saúde local, do relatório de gestão, e a criação do fundo municipal - conta exclusiva para o recebimento e aplicação das verbas da saúde.

É através dos conselhos que se exerce o controle social, que é a possibilidade da sociedade organizada de intervir nas ações do Estado, no gasto púbico, redefinindo-o na direção das finalidades sociais.

Cada conselho de políticas públicas possui identidade própria que pode ser apreendida a partir do desenho institucional e de sua trajetória política, ou seja, diferentes conselhos ou diferentes gestões de um mesmo conselho têm variações no que se refere à capacidade de incidir sobre as políticas, a maneira como dialogam com o governo, a sua dinâmica de participação. Portanto, os conselhos (das diversas esferas de políticas públicas) podem apresentar variações ou estágios diferenciados de desenvolvimento e consolidação de sua atuação e representação ${ }^{20}$.

Neste aspecto, a qualidade de representação do governo - sua transparência e capacidade ou possibilidade de diálogo - é uma importante variável na atuação do conselho. Assim como a unidade dos representantes da sociedade civil.

Nenhum governo - a despeito de sua coloração e inclinação partidária - pode hoje ignorar os conselhos nos processos de implementação da política ${ }^{20}$.

Os conselhos de saúde têm como objetivo o controle das iniciativas do Estado, de modo a assegurar a implantação da política de saúde em consonância com os princípios do SUS, e com a participação dos cidadãos na tomada de decisões do setor saúde.

Os conselhos de saúde têm atribuições deliberativas, são espaços de articulação entre Estado e sociedade nas três esferas de governo, têm composição plural e paritária (50\% dos membros dos conselhos são representantes da sociedade civil, e os demais representam prestadores de serviços, profissionais da área, e representantes do governo), são públicos e dialógicos. Sua base legal está na Constituição Federal de 1988, e tem como objetivo o controle, o monitoramento e a fiscalização da política de saúde ${ }^{1}$.

Os conselhos de saúde brasileiros estão regulados pela Lei 8142/199013 e têm sua normatização na atual Resolução n. $453 / 2012^{15}$, que é norteadora para que os conselhos funcionem de acordo com a Lei e, tendo sido sancionados pelos municípios desde o início da década de 1990, a partir de Leis municipais.

Em 2016, conforme o Conselho Nacional de Saúde (CNS), 4.539 ou 80,61\% dos conselhos existentes no país realizaram cadastramento dos seus dados no Sistema de Acompanhamento dos Conselhos de Saúde (SIACS) cujo objetivo é atualizar em uma única 
rede os dados referentes aos conselhos municipais de saúde dos municípios brasileiros, dos 26 conselhos estaduais, do Distrito Federal e dos 36 conselhos distritais de saúde indígena ${ }^{21}$.

Em 2016, 95,7\% dos 80\% conselhos municipais que fizeram o cadastramento estão regulamentados através de Lei Municipal, seguidos de 3,06\% por meio de decretos municipais e $1,24 \%$ através de portarias $^{21}$.

O cadastro não contemplou, na informação geral sobre cada conselho, se eles possuíam ou não Regimento Interno aprovado em plenária. Conforme determina a Resolução 453 de 201215, os conselhos necessariamente devem formular os Regimentos internos que definem normativamente a estrutura e a dinâmica dos mesmos.

A Resolução 453 de $2012^{15}$ implicou na criação de diretrizes para a criação, reformulação e funcionamento dos conselhos de saúde, revogando as diretrizes de números 33 de 1992, 319 de 2002, e 333 de 2003, mantendo, entretanto, as prerrogativas da Lei 8142 de 199013, ou seja, tais diretrizes definem também a questão da paridade, estrutura administrativa dos conselhos, a função da secretaria executiva, a periodicidade mensal das reuniões e a questão da prestação de contas a cada três meses pelo gestor ${ }^{15}$.

Os dados de 2016 trazem que 73,93\% dos municípios brasileiros que responderam ao cadastramento não cumprem com a paridade estabelecida pela Resolução 453 de $2012^{15}$, que estabelece que $50 \%$ das vagas devem ser entre entidades e movimentos representativos de usuários; $25 \%$ entre entidades representativas dos trabalhadores da área de saúde; e 25\% entre representantes de governo e prestadores de serviços privados conveniados ou sem fins lucrativos ${ }^{21}$.

Esta resolução também aponta que cabe ao Poder Executivo oferecer a infraestrutura adequada e necessária para o funcionamento desse órgão, exigindo que, portanto, ele disponibilize espaço físico, recursos materiais e humanos. Estes recursos devem estar garantidos em dotação orçamentária, mas essa é uma realidade que, na prática, não funciona como deveria.

Três questões importantes merecem ser assinaladas a respeito dos conselhos brasileiros: a participação destes na elaboração das políticas, discutindo os programas, ações, e a necessidade da alocação de recursos do orçamento para atender a esses programas e ações; o monitoramento e ou acompanhamento das ações e programas planejados exercendo o papel de fiscal das ações do governo; e a deliberação, aprovando ou não as prestações de contas das instâncias de governo.

Isso significa que o conselho tem que ter acesso a dados e documentos que permitam essas informações: o Plano de Saúde aprovado pelo CMS, os demonstrativos de receitas e despesas mensais, os processos licitatórios, como estão os contratos, convênios, auxílios e subvenções a entidades filantrópicas. E ainda referenda a Lei n. 8080/1990 que estabelece que os recursos financeiros do SUS sejam gastos sob acompanhamento e fiscalização dos conselhos ${ }^{22}$.

Estas questões levam a refletir que os conselhos expressam a correlação de forças existentes no conjunto da sociedade, uma vez que são instâncias sujeitas a conflitos de interesse, cooptação, e disputas da direção da política social articuladas a projetos societários, mesmo que isso não esteja explicitado ${ }^{23}$.

Neste aspecto, os conselheiros precisam se preparar ou serem capacitados para esta função, ou seja, precisam conhecer os princípios do SUS, a realidade local, e as funções de conselheiro, no que diz respeito a propor, monitorar, fiscalizar e deliberar sobre as ações do governo, e seus deveres e direitos enquanto conselheiro.

Apesar da legislação brasileira em vigor desde o ano $1990^{1}$ e da indicação da Resolução 453/201221, que traz a estrutura organizativa dos conselhos, o cadastro no SIACS trouxe dados que avaliam que muitos conselhos não estão em consonância com a Lei.

No que diz respeito a esta questão, no ano de 2010 foi realizada uma pesquisa com 06 conselhos municipais de saúde na área da 
DRS VIII, quando foi avaliado que destes, $100 \%$ foram criados através de Lei Municipal, e $67 \%$ possuem Regimento Interno, trazendo todas a normas de funcionamento destes conselhos ${ }^{16}$.

Apenas $17 \%$ possuíam Comissões técnicas que se organizam para estudar os temas a serem debatidos em reunião do conselho, e portanto, são fundamentais para trazer conhecimento sobre toda a ação desenvolvida pela Secretaria de Saúde dos municípios que representam ${ }^{16}$.

Destes conselhos, 83\% realizavam reuniões mensais, apesar de ser indicado que deveriam ser realizadas reuniões mensalmente. $83 \%$ dos presidentes foram eleitos pelo colegiado, 33\% tem paridade das representações representante violação à Legislação ${ }^{16}$.

Dos conselhos $50 \%$ tinham suas pautas enviadas com antecedência para os conselheiros, o que permite que estes conselheiros pudessem consultar suas bases sobre assuntos que seriam discutidos ou deliberados. Todas estas situações pontuais indicam que em algumas situações os conselhos estudados não estavam em consonância com a Resolução 333/200314, em vigor à época da pesquisa, ou com a Resolução $453 / 2012^{15}$, atual, que determina a normatização e organização dos conselhos ${ }^{16}$.

Quanto à captação das demandas e vocalização das ações deliberadas à população ou aos segmentos organizados, observou-se que não existe um canal definido de captação de demandas da população. Os conselheiros entrevistados alegaram que não têm o hábito de consultar as suas bases sobre os assuntos que serão discutidos e deliberados e também não têm um mecanismo formal de informação enquanto órgão de participação.

Isso leva à reflexão de que os conselhos conseguirão se firmar enquanto mecanismo de participação deliberativa quando conseguirem se mostrar à sociedade. Na mesma linha de raciocínio, uma vez conhecidos como órgãos de participação e vocalização das demandas, conselhos e conselheiros terão melhores condições de se articularem com a população.
Neste sentido, e para medir esta possibilidade, foram verificados quais os meios utilizados para vocalizar as ações dos conselhos, como: páginas da internet, jornais, rádios, folhetos ou outros ${ }^{16}$.

Os dados mostraram que nenhum dos Conselhos Municipais de Saúde avaliados tem um mecanismo formal de informação enquanto órgão de participação. Com relação aos representantes do governo, normalmente as secretarias de saúde, na figura de seu Secretário ou seu representante legal, são convidadas, ocasionalmente, pela imprensa local (radio e jornal) a dar informações ou esclarecimentos sobre situações pontuais, ou seja, em 50\% dos municípios estudados existem informações fornecidas pelas Secretarias de Saúde aos usuários. Entretanto, estas informações não têm qualquer ligação com os Conselhos Municipais de Saúde ${ }^{16}$.

Quanto aos representantes, observa-se que também não divulgam ou informam seus representados sobre as ações deliberadas nos conselhos. Acontecem manifestações individuais destes conselheiros, pontualmente informando questões aos que representam, mas não no que se refere à totalidade das ações e deliberações, nestes espaços $^{16}$.

\section{CONCLUSÃO}

A participação social é uma conquista construída ao longo da história e contempla momentos de avanços, mas, a participação através dos conselhos ainda tem muitos desafios pela frente.

Os conselhos no Brasil foram criados e normatizados, mas observa-se, através da amostra representativa, que quanto à organização, os conselhos brasileiros não estão adequados às resoluções atuais.

A representatividade dos conselhos ainda é frágil, pois os conselheiros não procuram suas bases para a discussão de assuntos pertinentes à coletividade. Isto mostra a necessidade de que os conselheiros recebam capacitação. Aliada a isso, a 
vocalização das ações e deliberações dos Conselhos também se mostra frágil.

Observa-se que os mecanismos participativos que existem no Brasil, com a experiência dos conselhos de políticas públicas, são muito grandes e complexos, mas que ao mesmo tempo atendem a todo o território nacional brasileiro e apesar das diferenças locais e regionais, apresentam ricas experiências.

0 modelo atual de prática participativa e de controle social, através dos conselhos, nasceu a partir das aspirações dos sanitaristas e dos movimentos sociais.

Este formato cresceu, consolidou-se, e é um dos mecanismos, hoje, de maior visibilidade. Apesar do indiscutível progresso, apresenta limites e necessários avanços para consolidar-se como prática coletiva. Neste quesito, ações propositivas são necessárias para envolver a construção da cidadania desde a formação do cidadão na vida escolar e na vida familiar, até seu engajamento enquanto cidadão que se vê e se sente como sujeito, não só de direitos, mas também, de deveres e responsabilidades.

Dois aspectos parecem de extrema importância: o processo de eleição dos conselheiros e a prática da organização de comissões de trabalho que levam a deliberações efetivas. É necessária a garantia de processos de seleção inclusivos, com presença de eleição e abertura do conselho para o maior número possível de diferentes entidades, ou seja, o processo de eleição deve ser bastante divulgado pelos órgãos da mídia escrita e falada, o que oportuniza para a população o conhecimento deste espaço de participação, e, ainda, que esta possa atuar não somente da eleição, mas também nos processos decisivos.

Outro aspecto diz respeito a estimular que os conselhos criem uma organização interna de comissões, comitês ou grupos de trabalho, o que possibilita maiores debates, tomada de consciência, e maior aprofundamento de determinados assuntos e temas tratados para posterior deliberação.

A ação de deliberação deve ser o resultado das negociações entre os diversos segmentos, com o objetivo de discutir e contemplar seus interesses nas políticas públicas.

\section{REFERÊNCIAS}

1. Presidência da República (Brasil). Constituição da República Federativa do Brasil de 1988. [Internet]. D.O.U., Brasília, DF, 5 out 1988 [citado em 10 set 2016]. Disponível em: http://www.planalto.gov.br/ccivil_03/Constituicao/Co nstituicao.htm.

2. Avritzer L, Ramos A. Democracia, escala y participación. Reflexiones desde lãs instituciones participativas brasileñas. Rev Int Sociol. 2016; 74(3):1-15.

3. Coutinho CN. Cidadania e modernidade. Perspectivas. 1999; 22:41-59.

4. Luiz LT. A cidadania no espaço público e privado. [tese]. Franca, SP: Faculdade de História, Direito e Serviço Social, Universidade Estadual Paulista "Júlio de Mesquita Filho"; 2006.

5. Cohen J. Democracia y libertad. In: Elster J., org. La democracia deliberativa. Traducción de José María Lebrón. Barcelona: Gedisa; 2013.

6. Sousa Santos B, Avritzer L. Para ampliar o cânone. In: Avritzer L, et. al., orgs. Democracia, república e participação: curso de atualização. Belo Horizonte: UFMG; 2008.

7. Oliveira EA. Participação democrática. [monografia]. Belo Horizonte: Instituto de educação continuada, Pontifícia Universidade Católica; 2005.

8. Ribeiro N, Raichelis R. Revisitando as influências das agências internacionais na origem dos conselhos de políticas públicas. Serv Soc Soc. 2012; 109:45-67. 9. Bobbio N. O futuro da democracia: uma defesa das regras do jogo. Rio de Janeiro: Paz e Terra; 2015.

10. Gohn MG. Conselhos gestores e participação sociopolítica. 4ed. São Paulo: Cortez; 2011.

11. Soares GS. Entre o projeto de modernidade e a efetivação da democracia: marcas deixadas na construção da vida social brasileira. Serv Soc Soc. 2012; 109:31-44.

12. Antunes R. Os sentidos do trabalho: ensaio sobre a afirmação e a negação do trabalho. São Paulo: Boitempo; 2015.

13. Presidência da República (Brasil). Lei n. 8142, 28 de dezembro de 1990. Dispõe sobre a participação da comunidade na gestão do Sistema Único de Saúde (SUS) e sobre as transferências intergovernamentais de recursos financeiros na área da saúde e dá outras providências [Internet]. D.O.U., Brasília, DF, $31 \mathrm{dez}$ 1990 [citado em 9 set 2016]. Disponível em: http://www.planalto.gov.br/ccivil_03/leis/L8142.h tm.

14. Ministério da Saúde (Brasil). Resolução n.o 333, de 4 de novembro de 2003. Aprova as diretrizes para criação, reformulação, estruturação e funcionamento dos Conselhos de Saúde [Internet]. D.O.U., Brasília, DF, 4 dez. 2003 [citado em 9 set 
2016].

Disponível

em:

http://conselho.saude.gov.br/ultimas_noticias/200 5/resolucao333.htm.

15. Ministério da Saúde (Brasil). Resolução 453, 10 de maio de 2012. Aprova as diretrizes para instituição, reformulação, reestruturação e funcionamento dos Conselhos de Saúde [Internet]. D.O.U., Brasília, DF, 17 jul 2012 [acesso em 12 set 2016]. Disponível em: http://conselho.saude.gov.br/ultimas_noticias/201 2/12_jun_resolucao453.html

16. Liporoni AARC. Os caminhos da participação e do controle social na saúde: estudo das realidades do Brasil e Espanha. [tese]. Franca: Faculdade de Historia, Direito e Serviço Social, Universidade Estadual Paulista "Júlio de Mesquita Filho"; 2010.

17. Faria CF. Os determinantes da efetividade democrática da participação social. In: Avritzer, L, et. al., orgs. Democracia, república e participação: curso de atualização. Belo Horizonte: UFMG; 2008.

18. Stotz EN. Trajetória, limites e desafios do controle social do SUS. Saúde Debate. 2006; 30(73/74):149-60.

19. Carvalho AI. Conselhos de saúde, responsabilidade pública e cidadania: a reforma sanitária como reforma do Estado. In: Fleury S., org.
Saúde e democracia: a luta do CEBES. São Paulo: Lemos; 1997.

20. Almeida C, Tatagiba L. Os conselhos gestores sob o crivo da política: balanços e perspectivas. Serv Soc Soc. 2012; 109:68-92.

21. Ministério da Saúde (Br). Sistema de Acompanhamento dos Conselhos de Saúde (SIACS). Brasília, DF: CNS; 2016 [acesso em 9 set 2016]. Disponível em: http://conselho.saude.gov.br/web_siacs/index.html

22. Presidência da República (Brasil). Lei n. 8.080, 19 de setembro de 1990. Dispõe sobre as condições para a promoção e recuperação da saúde, a organização e o funcionamento dos serviços correspondentes e dá outras providências. Lex: Legislação Federal e Marginalia. 1999; 54:10601073.

23. Bravo MIS, Correia MVC. Desafios do controle social na atualidade. Serv Soc Soc. 2012; 109:109-26.

\section{CONTRIBUIÇÕES}

Andréia Aparecida Reis de Carvalho Liporini realizou levantamento bibliográfico e redação do artigo.

\section{Como citar este artigo (Vancouver)}

Liporoni AARC. A defesa da saúde pública através dos conselhos municipais de saúde. REFACS [Internet]. 2017 [citado em: inserir dia, mês e ano de acesso]; 5(Supl 2):335-345. Disponível em: link de acesso e DOI.

\section{Como citar este artigo (ABNT)}

LIPORONI, A. A. R. C. A defesa da saúde pública através dos conselhos municipais de saúde. REFACS, Uberaba, v. 5, p. 335-345, 2017. Supl. 2. Disponível em: <link de acesso>. Acesso em: inserir dia, mês e ano de acesso. DOI:

\section{Como citar este artigo (APA)}

Liporoni, A. A. R. C. (2017). A defesa da saúde pública através dos conselhos municipais de saúde. REFACS, 5(Supl 2), 335-345. Recuperado em: inserir dia, mês e ano de acesso de inserir link de acesso e DOI. 